\title{
Botanical Investigation Of Fallopia Dumetorum (L.) Holub (Polygonaceae) And Qualitative And Quantitative Assessment Of Its Polyphenolic Compounds
}

\author{
Olaru OT¹, Ancuceanu RV¹, Anghel Adriana luliana1, Dinu Mihaela¹, Seremet Oana Cristina², Istudor \\ Viorica $^{3}$
}

\begin{abstract}
1 Department of Pharmaceutical Botany and Cellular Biology, "Carol Davila" University of Medicine and Pharmacy, Bucharest, Romania
2 Department of Pharmacology and Clinical Pharmacy, "Carol Davila" University of Medicine and Pharmacy, Bucharest, Romania

3 Department of Pharmacognosy, Phytochemistry and Phytotherapy, "Carol Davila" University of Medicine and Pharmacy, Bucharest, Romania
\end{abstract}

Background: Considering the continuous need to find new sources of polyphenolic compounds, we performed a pharmacognostical examination of the species Fallopia dumetorum (L.) Holub sin. Polygonum dumetorum L. (Polygonaceae). The plant is common in the plain regions of Romania and has not been exploited therapeutically.

Materials and method: Microscopic examination was performed on cross-sections, surface preparations and on powder obtained from the aerial parts of the flowering plant. Qualitative chemical analysis was realized by phytochemical screening and thin layer chromatography (TLC). Phenolic compounds were assayed by spectrophotometric methods: flavonoids expressed as rutin (with aluminium chloride), phenolcarboxylic acids expressed as chlorogenic acid (Arnow's method) and proanthocyanidins expressed as cyanidin chloride (in acidic medium, by conversion to anthocyanins).

Results: The species has the following microscopic characters: anomocytic stomata, druses of calcium oxalate, sessile, pluricellular glandular hairs and pollen grains with smooth exine. Polysaccharides, reducing compounds, coumarins, sterols/triterpenes, phenol-carboxylic acids, flavones, proanthocyanidins, tannins and carotenoids were identified by phytochemical screening; chlorogenic acid, caffeic acid, quercetin and stigmasterol/beta-sitosterol were detected by TLC. F. dumetori herba has a content of $1.49 \pm 0.105 \mathrm{~g} \%$ polyphenol-carboxylic acids, 0.40 $\pm 0.087 \mathrm{~g} \%$ flavonoids and $0.18 \pm 0.002 \mathrm{~g} \%$ proanthocyanidins.

Conclusions: We have characterized pharmacognostically the native species $F$. dumentorum. Due to its content in phenolic compounds it might serve as a source of polyphenols.

Keywords: Fallopia dumetorum, phenolic compounds, thin layer chromatography, spectrophotometry, microscopy

Received: 13 June 2013 / Accepted: 9 April 2014

\section{Introduction}

Polyphenolic compounds are of a particular interest lately due to the numerous pharmacological actions attributed to them. Recent research on the antioxidant properties of polyphenols have demonstrated several therapeutic actions: anti-inflammatory [1-3], hepatoprotective [4], anticancer [3], hypoglycemic [5], of prevention of atherosclerosis [3] and Alzheimer's disease [6]. Furthermore, the research of their antiulcer, antimicrobial and antiviral actions have yielded positive results $[7,8]$.

Studies of the pharmacological activity of phytocomplexes obtained from different Fallopia genera species indicated their usefulness in diabetes, liver disease, hypercholesterolemia and other diseases. Extracts from $F$. japonica (Houtt.) Ronse Decr. have hypoglycemic activity by inhibiting the activity of $\alpha$-D-glucosidase, invertase, and lactase, and to a limited extent by inhibiting the activity of $\alpha$-amylase $[9,10]$. The hepatoprotective activity of $F$.

Correspondence to: Adriana luliana Anghe

E-mail: anghel_adriana_iuliana@yahoo.com japonica and F. multiflora (Thunberg) Haraldson was evidenced in several studies on CCl4-induced liver injury in rats and mice and on liver cell cultures $[11,12]$.

Fallopia dumetorum (L.) Holub sin. Polygonum dumetorum $\mathrm{L}$. is a herbaceous annual plant, with voluble stem, native to Europe, Northen Africa, Turkey, the Caucasus, Northen Iran, Southern and Western Siberia, Central Asia, Japan and introduced in Northern America [13-15].

The chemical composition has been scarcely investigated and only the flavonoid fraction has been characterized from a qualitative point of view, for taxonomic purposes; the aerial parts contained heterosides of kaempferol (3-Ogalactoside, 3-O-glucoside), quercetin (3-O-galactoside, 3-O-glucoside), apigenin (6-C-glucoside, 8-C-glucoside) and luteolin (8-C-glucoside) [16].

The species is traditionally used for its laxative and purgative action in the Srinagar region (Himalayas) $[17,18]$. Bibliographic sources do not mention neither the part of the plant, nor the mode of administration.

The plant is common in the plain regions of Romania and has not been exploited therapeutically. Having in 
mind its relatedness to the species mentioned above and the continuous need to identify new sources of polyphenols, we performed a botanical, qualitative and quantitative chemical analysis of polyphenolic compounds of the species F. dumetorum (L.) Holub.

\section{Methods}

The plant material was collected from Zimnicea, Teleorman county, Romania, in June 2011, during the blooming period.

\section{Microscopic examination}

The microscopic examination was performed on manually executed cross sections of the root, stem, petiole and leaf and surface preparations from leaf and flower. The cross sections were clarified with Javel water and double stained with iodine green and alum-carmine; the surface preparations were clarified with a $5 \% \mathrm{NaOH}$ solution [19]. The microscopic preparations were analyzed using a Labophot 2-Nikon microscope (ocular 10×, ob. 4×, 10×, 40×) coupled with a Nikon $70 \mathrm{D}$ digital camera.

The qualitative chemical analysis was performed on the flowering aerial parts, through phytochemical screening and thin layer chromatograpy (TLC).

\section{TLC analysis and phytochemical screening}

Sample preparation: $5.00 \mathrm{~g}$ of dry plant material were extracted with different polarity solvents. First the product macerated for $24 \mathrm{~h}$ at room temperature with $25 \mathrm{~mL}$ diethyl ether, then refluxed for 30 minutes, first with $50 \mathrm{~mL}$ methanol, then with $50 \mathrm{~mL}$ distilled water. The extractive solutions were coded as $\mathrm{PD}_{\mathrm{Eth}}$ (the etheric solution), $\mathrm{PD}_{\mathrm{M}}$ (the methanolic solution) and $\mathrm{PD}_{\mathrm{A}}$ (the aqueous solution). Aliquots of $25 \mathrm{ml}$ of the $\mathrm{PD}_{\mathrm{M}}$ and the $\mathrm{PD}_{\mathrm{A}}$ solutions were subjected to acid hydrolysis with HC1 1M, 1:1 (v/v), then extracted with diethyl ether ( 3 times with $10 \mathrm{ml}$ ). The combined etheric solutions, dehydrated on anhydrous $\mathrm{Na}_{2} \mathrm{SO}_{4}$ and filtered, were concentrated on the water bath, up to $5 \mathrm{ml}$. The obtained solutions were coded as $\mathrm{PD}_{\mathrm{MH}}$ and $\mathrm{PD}_{\mathrm{AH}}$.

The chemical screening was performed through characteristic chemical reactions described in the literature for the following classes of phytocompounds: polysaccharides, reducing compounds, coumarins, sterols/triterpenes, phenol-carboxylic acids, flavones, anthocyanidins, proanthocyanidins and tannins, carotenoids [20].

For the identification of flavonoids, phenol-carboxylic acids and sterols TLC was performed.

Chromatography conditions:

- stationary phase: silica gel $60 \mathrm{~F} 254$ on an Al/plastic support (Merck);

- mobile phase: chloroform - acetone, 80:20 (v/v), for the identification of the sterols [21]; ethyl acetate formic acid - water, 1:1:8 (v/v) for the identification of glycosides; toluene - ethyl acetate - formic acid, $5: 3: 1(\mathrm{v} / \mathrm{v})$, for the identification of the aglycones [22];
- reference substances: (dissolved in ethanol 96\%): $\beta$-sitosterol, stigmasterol, caffeic acid, chlorogenic acid, quercetin, kaempferol, myricetin, rutin trihydrate $(1 \mathrm{mg} / \mathrm{mL})$ and hyperoside, isoquercitroside $(0.2 \mathrm{mg} / \mathrm{mL})$ (Sigma Aldrich).

- reagents: acetic anhydride, sulfuric acid - ethanol, 1:1 (v/v) (reagent 1) - for the sterols; Natural Reagent Product (diphenylboric acid aminoethyl ester) $=$ PEG (Neu/Peg. No. 28) (reagent 2) - for the flavonoids $[23,24]$.

\section{Phenolic compounds assay}

Sample preparation:

- for phenol-carboxylic acids and flavonoid assays: $1.000 \mathrm{~g}$ plant material was extracted with $50 \mathrm{~mL}$ ethanol $50 \%$ at reflux: after cooling, the solution was filtered and completed to $50 \mathrm{~mL}$ with solvent;

- for the proanthocyanidins assay: $1.000 \mathrm{~g}$ of plant material were treated with $50 \mathrm{~mL} \mathrm{HCl} 2 \mathrm{~N}$ and refluxed for $45 \mathrm{~min}$; after cooling, the solution was filtered and twice extracted with $20 \mathrm{~mL}$-butanol in a separation funnel and the volume of the two combined upper layers was completed to $50 \mathrm{~mL}$ with $\mathrm{n}$-butanol.

Phenolic compounds content was determined by spectrophotometric methods with a UV/Vis Jasco V650 spectrometer.

The assay of flavonoids was performed according to the Romanian Pharmacopoeia, 10 ${ }^{\text {th }}$ Ed. - Cynarae folium monograph [25]. The total flavonoids content was expressed as rutin by interpolating the results on a calibration curve. The calibration curve was plotted by preparing rutin solutions at concentrations between 15 and $40 \mu \mathrm{g} / \mathrm{mL}$ in ethanol $50 \%$, and registering the samples absorbance at $\lambda=420 \mathrm{~nm}$.

Total phenol-carboxylic acids content was estimated according to the European Pharmacopoeia $6^{\text {th }}$ Ed. - Fraxini folium monograph [26]; the method is based on Arnow's reaction with $\mathrm{HNO}_{2} / \mathrm{HCl}$, and the measuring of the oxime absorbance at $\lambda=525 \mathrm{~nm}$; results were expressed as chlorogenic acid ( $\mathrm{g} \%)$.

Total proanthocyanidins content was assayed according to Lebreton method by converting the proanthocyanidins in acidic medium to anthocyanins, and measuring the samples absorbance at $\lambda=550 \mathrm{~nm}$; results are expressed as cyanidin chloride [27].

\section{Results}

The microscopic examination of the root cross sections revealed a secondary structure with sclerenchyma fibers (Figure 1). The ridged circular stem presents the following characteristics: lacunar collenchyma (under the ridges), cortical parenchyma with calcium oxalate druses and continuous sclerenchyma formation all round the stem (Figure 2). The leaf blade has a dorsi-ventral structure with two collateral vascular bundles and unicellular trichomes on the surface of the epidermis (Figure 3). The petiole presents a 


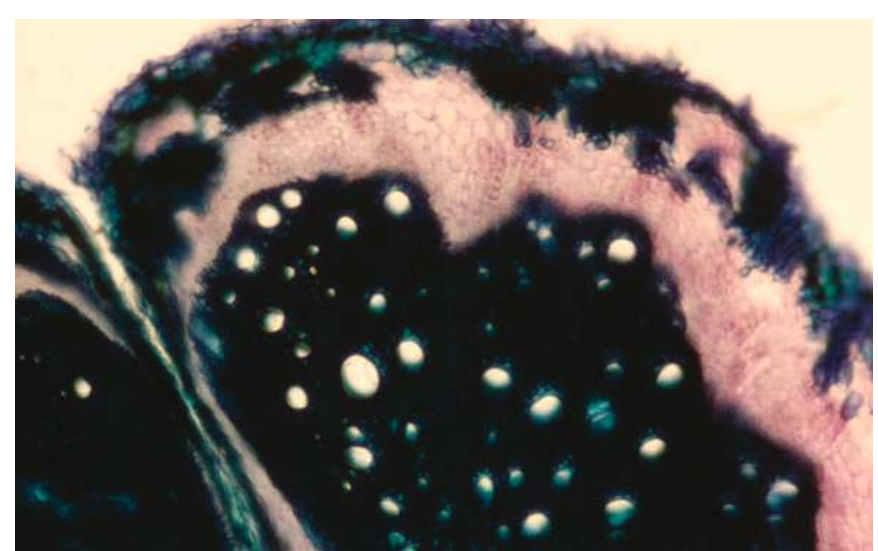

Fig. 1. The root cross-section (40x)

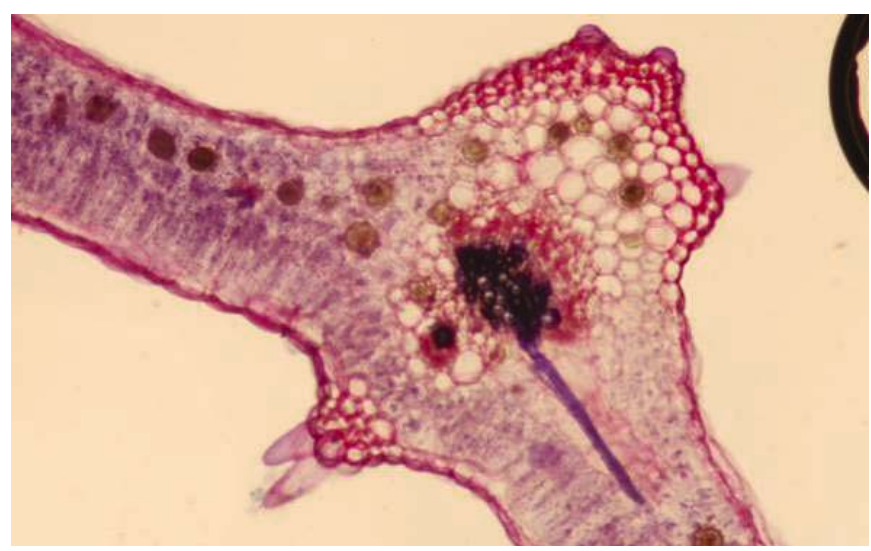

Fig. 3. The leaf cross-section (40x)

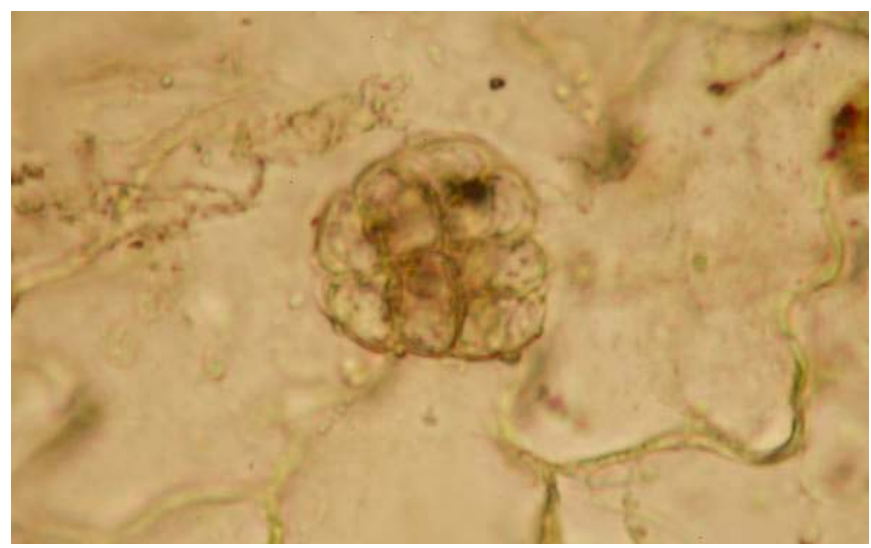

Fig. 5. Leaf surface preparation (400x)

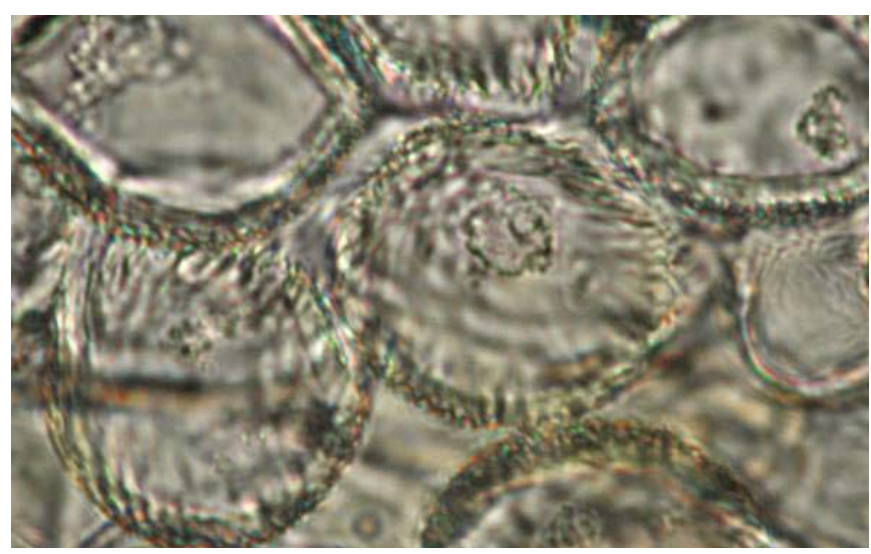

Fig. 7. Flower surface preparation (400x)

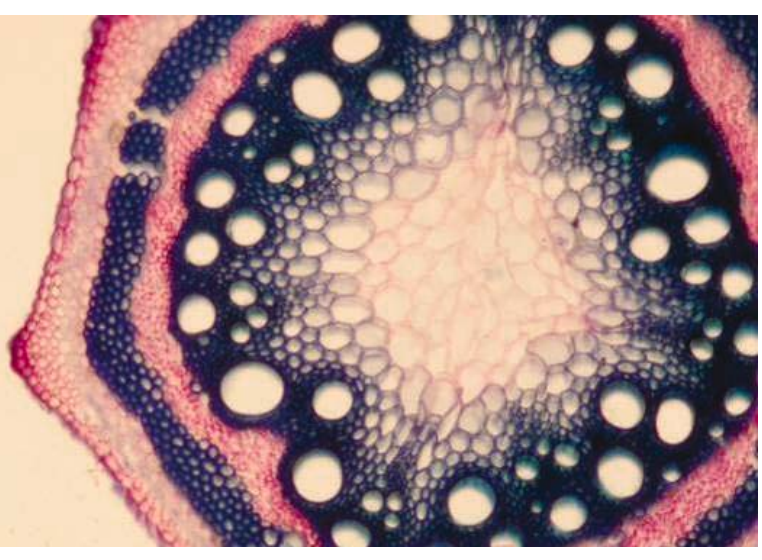

Fig. 2. The stem cross-section (40x)

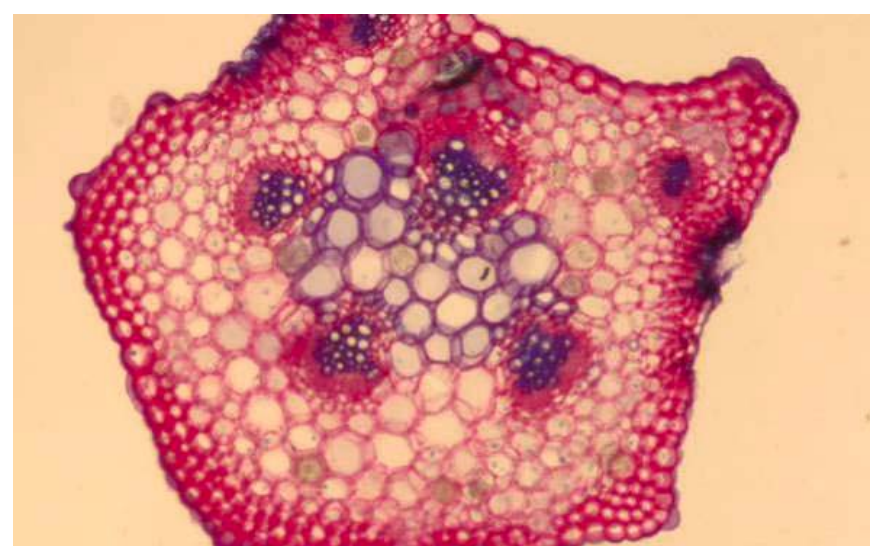

Fig. 4. The petiole cross-section (40x)

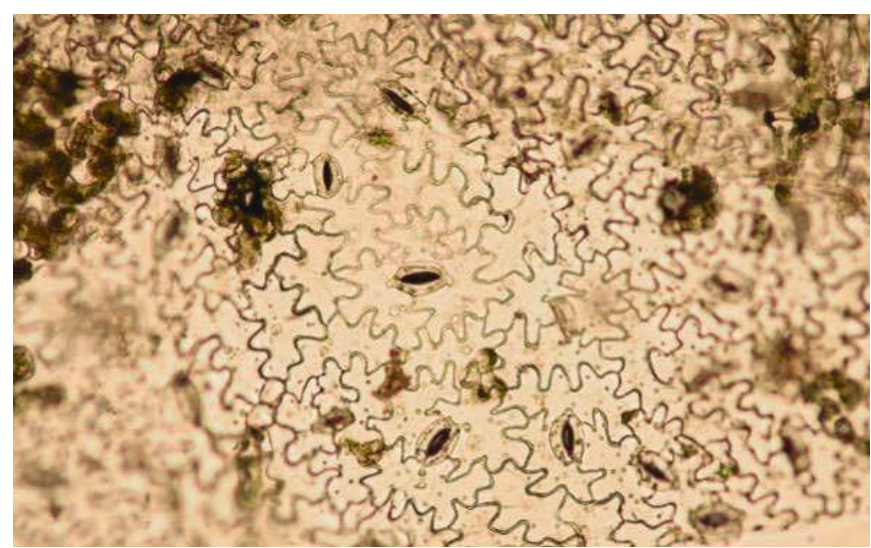

Fig. 6. Leaf surface preparation (100x)

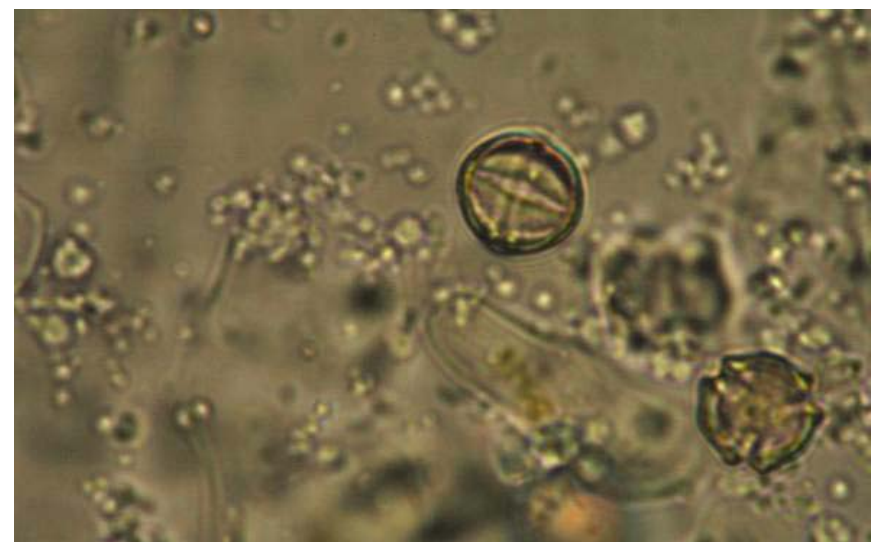

Fig. 8. Flower surface preparation (400x) 


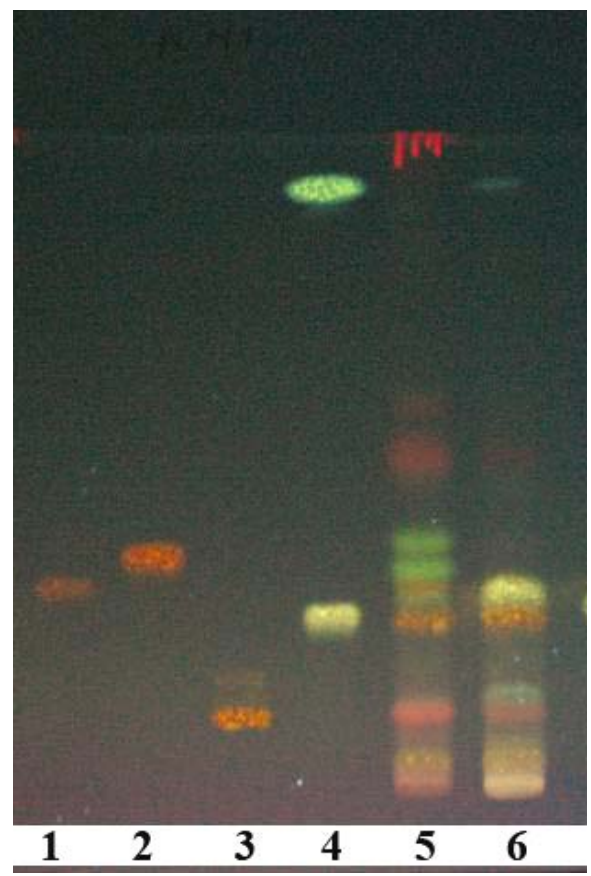

Fig. 9. Heterosides TLC plate: 1 - hyperoside , 2 - rutin, 3 - izoquercitrin, 4 - chlorogenic acid, caffeic acid, $5-\mathrm{PD}_{\mathrm{M}}, 6-\mathrm{PD}_{\mathrm{A}}$

semicircular structure with two obvious margins, lacunar collenchyma and 6 vascular bundles (Figure 4). The examination of the surface preparations revealed: calcium oxalate druses, pluricellular sessile glandular trichomes (Figure 5), anomocytic stomata (Figure 6) - in the leaf; unicellular papillae (Figure 7) and pollen grains with smooth exine (Figure8) - in the flower.

By phytochemical screening, polysaccharides, reducing compounds, coumarins, sterols/triterpenes, phenolcarboxylic acids, flavones, proanthocyanidins and tannins, carotenoids were identified. fied:

Through TLC, the following compounds were identi-

- chlorogenic acid (green fluorescence, $\mathrm{Rf}=0.52$, in $\mathrm{PD}_{\mathrm{A}}$ and $\mathrm{PD}_{\mathrm{M}}$ ) (Figure 9);

- caffeic acid (green fluorescence, $\mathrm{Rf}=0.97$ in $\mathrm{PD}_{\mathrm{A}}$ )

(Figure 9);

- quercetin (orange fluorescence, $\mathrm{Rf}=0.45$ in $\mathrm{PD}_{\mathrm{Mh}}$ );

- stigmasterol $/ \beta$-sitosterol $(\mathrm{Rf}=0.76)$ (Figure 10).

\section{Phenolic compounds assay}

A six point linear calibration curve of rutin in the 15-40 $\mu \mathrm{g} / \mathrm{mL}$ range with good linearity $(\mathrm{R}=0.9997 ; \mathrm{y}=0.0230 \mathrm{x}$ $-0.0125)$ was obtained.

Table I. Phenolic content of $F$. dumetori herba

\begin{tabular}{lcc}
\hline Phenolic compound & \multicolumn{2}{c}{ Content $(\mathrm{g} \%)$} \\
\cline { 2 - 3 } & $\mathrm{M} \pm \sigma, \mathrm{n}=5$ & $95 \% \mathrm{Cl}$ \\
\hline Total phenol-carboxylic acids & $1.49 \pm 0.105$ & $1.224-1.748$ \\
Total flavonoids & $0.40 \pm 0.087$ & $0.288-0.503$ \\
Total proanthocyanidins & $0.18 \pm 0.002$ & $0.175-0.185$ \\
\hline
\end{tabular}

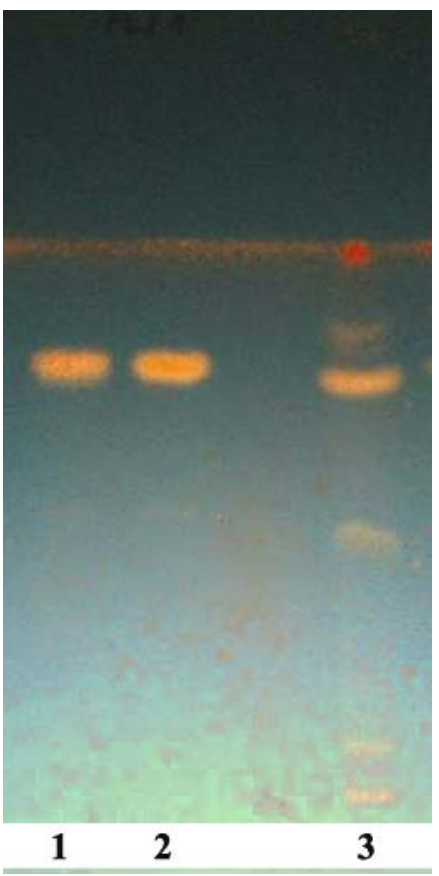

Fig. 10. Sterols TLC Plate: 1 - $\beta$-sitosterol, 2 - stigmasterol, 3 $P D_{\text {eth }}$

The results (mean \pm standard deviation, 95\% confidence interval) of quantitative determinations are shown in Table I.

\section{Discussion}

The analyzed species can be identified by: sclerenchyma fiber packages (root), continuous sclerenchyma formation (stem), lacunar collenchyma (stem, leaf), unicellular trichomes and multicellular glandular sessile trichomes (stem, leaf), calcium oxalate druses (stem, leaf), anomocytic stomata (leaf) and pollen grains with smooth exine (flower). To the best of our knowledge, the microscopic characterization of this species has not been investigated. The elements observed in stem, leaf and petiole cross sections are similar with the ones described for $F$ a aubertii, which is a related species. The anatomical particularities revealed in the leaves and flowers surface preparations from the two species are also similar [28]. However, $F$. dumetorum can be differentiated from $F$ aubertii by the shape of the stem cross sections (smooth at $F$ aubertii and with ridges at $F$. dumetorum) and the presence of lacunar collenchyma under the stem ridges.

Flavonoid aglycons in natural state (in the absence of hydrolysis) could not be detected in the plant material; they could be identified only after acid hydrolysis. Rutin, hyperoside, kaempferol, apigenin and luteolin were not identified in any of the extracts tested, altrough they are mentioned in the literature [16]. Instead, we have shown the presence of free phenolic acids (chlorogenic acid, caffeic acid) in the tested extracts, a finding not previously reported. The TLC analysis can be used for the differentiation of $F$. dumetorum from the related species $F$. convolvulus and $F$ aubertii in which rutin, hyperoside, isoquer- 
citrin, myricetin and kaempferol were additionally found $[28,29]$.

The content of flavonoid compounds in the aerial part of $F$. dumetorum $(0.4 \mathrm{~g} \%)$ is considerably lower than that reported for $F$. multiflora (2.74 g\%)[30], but the phenolcarboxyllic acid contents is relatively high $(1.49 \mathrm{~g} \%)$.

\section{Conclusions}

We have characterized pharmacognostically the native species $F$. dumentorum. The main histo-anatomical elements are: continuous sclerenchyma formation, lacunar collenchyma under the ridges of the stem and unicellular trichomes and multicellular glandular sessile trichomes on the epidermis of the leaf. A relatively high content of phenolic acids was found and chlorogenic acid, caffeic acid and quercetin were identified. Due to its content in phenolic compounds, F. dumetorum may serve as a source of polyphenols.

\section{Acknowledgement}

This paper is supported by the Sectoral Operational Programme Human Resources Development (SOP HRD), financed from the European Social Fund and by the Romanian Government under the contract number POSDRU/6/1.5/S/1.

\section{References}

1. Taie AAH, El-Mergawi R, Radwan S. Isoflavonoids, Flavonoids, Phenolic Acids Profiles and Antioxidant Activity of Soybean Seeds as Affected by Organic and Bioorganic Fertilization. American-Eurasian J. Agric. \& Environ. Sci. 2008;4(2):207-213.

2. González-Gallego J, Sánchez-Campos S, Tuńón MJ. Anti-inflammatory properties of dietary flavonoids. Nutr. Hosp. 2007;22(3):287-293.

3. Garclá-Lafuente A, Guillamón E, Villares A, Rostagno MA, Martínez JA. Flavonoids as anti-inflammatory agents: implications in cancer and cardiovascular disease. Inflamm. Res. 2009;58:537-552.

4. Adewusi EA, Afolayan AJ. A review of natural products with hepatoprotective activity. J Med. Plants Res. 2010;4(13):1318-1334.

5. Brahmachari G. Bio-flavonoids with promising antidiabetic potentials: A critical survey, Opportunity, Chall. Sc. Nat. Prod. in Med. Chem. 2011;1: 187-212.

6. Uttara B, Singh AV, Zamboni P, Mahajan RT. Oxidative Stress and Neurodegenerative Diseases: A Review of Upstream and Downstream Antioxidant Therapeutic Options. Curr Neuropharmacol. 2009;7(1):65-74.

7. Devasagayam TPA, Tilak JC, Boloor KK, et al. Free Radicals and Antioxidants in Human Health: Current Status and Future Prospects. JAPI. 2004;52:794-804.

8. Tapas AR, Sakarkar DM, Kakde RB. Flavonoids as Nutraceuticals: A Review. Trop. J. Pharm. Res. 2008;7(3):1089-1099.
9. Soumyanath A. Traditional Herbal Medicines for Modern Times: Antidiabetic Plants, Boca Raton, CRC Press, 2006, p. 29, 293-295.

10. Tang WQ, Shen Z, Yin JW. Inhibitory Activity to Glycosidase of Tannins from Polygonum cuspidatum. Nat. Prod. Res. Dev. 2006;2:1-9.

11.Zhang $\mathrm{H}$, Yu CH, Jiang YP, et al. Protective Effects of Polydatin from Polygonum cuspidatum against Carbon Tetrachloride-Induced Liver Injury in Mice. PLoS One. 2012;7(9):564-574.

12. Noda T, Zamada T, Ohkubo T, et al. Hot-water-extracts of Polygonum multiflorum do not induce any toxicity but elicit limited beneficial on the liver in mice. J. Health.Sci. 2009;55(5):720-725.

13. ${ }^{* \star *}$ Flora Nordica, volume 1: Lycopodiaceae to Polygonaceae, Stockholm, The Bergius Foundation, The Royal Swedish Academy of Sciences, 2000, pp. 274-276.

14. ${ }^{* \star *}$ Flora of North America, vol. 5 Magnoliophyta: Caryophyllidae, part. 2, New York, Oxford University Press, 2005, pp. 479-481.

15. ${ }^{\star \star \star}$ Flora Republicii Populare Române, vol I, București, Ed. Academiei, 1952, pp. 474-476.

16. Kim MH, Park JH, Park CW. Flavonoid chemistry of Fallopia section Fallopia (Polygonaceae). Biochem. Syst.Ecol. 2000;28:433-441.

17. Singh DG, Kachroo P. Forest Flora of Srinagar., Delhi, Bishen Singh Mehendra Pal Singh, 1976, pp. 233.

18. Hussain F, Shah SM, Sher H. Traditionnal resource evaluation of some plants of Mastuj, district chitral, Pakistan. Pak. J. Bot. 2007;39(2):339354.

19. Dinu M, Ancuceanu RV, Hovaneț MV, Anghel Al, Crețu OD, Rebegea OC, Olaru OT. Botanică farmaceutică, Baze teoretice și Practice: Citologie, Histologie, organografie, București, Ed. Universitară, 2009, pp. 58-62, 71-73.

20. Evans WC. Trease \& Evans' Pharmacognosy, $15^{\text {th }}$ edition, Saunders Company, 2002, pp. 193, 223-224, 227-230, 246-247, 250-252, 289290, 336-337.

21. Pavel M, Voștinaru O, Mogoșan C, Ghibu S. Phytochemical and Pharmacological Research on Some Extracts Obtained from Serpylli Herba. Farmacia. 2011;59(1):77-84.

22. Waksmundzka-Hajnos M, Sherma J, Kowalska T. Thin Layer Chromatography in Phytochemistry, Boca Raton, CRC Press, 2008, p. 82.

23. Packer L. Methods in Enzymology, vol. 335: Flavonoids and Other Polyphenols, San Diego, Academic Press, 2001, pp. 5-8.

24. Jork H, Funk W, Wimmer H. Thin-Layer Chromatography Reagents and detection Methods. Weinheim. 1990:277-283.

25. ${ }^{* \star *}$ Farmacopeea Română ediția a X-a, București, Editura Medicală, 2000, p. 334, 335.

26. ${ }^{\star \star *}$ European Pharmacopoeia, $6^{\text {th }}$ Edition, Strassbourg, Council of Europe, 2008, p. 1027.

27. Lebreton P, Jay M, Voirin B. Sur l'analyse qualitative et quantitative des flavonoides. Chim. Anal. Fr. 1967;49:375-383.

28. Olaru OT, Anghel Al, Istudor V, Ancuceanu RV, Dinu M. Contributions to the pharmacognostical and phytobiological study of Fallopia aubertii (L. Henry) Holub. (Polygonaceae). Farmacia. 2013;61(5):991-999.

29. Olaru OT, Anghel Al, Istudor V, Olaru II. The qualitative and quantitative determination of the phenolic compounds in Polygonum convolvulus $L$. species, Polygonaceae family. Acta Medica Marisiensis. 2013;59(2):162164.

30. Dong D, Dong SF, Han LQ, Zhao WX, Jianhua L. Polygonum multiflorum content of total flavonoids and trace elements analysis and its efficacy mechanism. Available online at: http://eng.hi138.com/medicine-papers/ pharmacy-papers/200909/131451_polygonum-multiflorum-contentof-total-flavonoids-and-trace-elements-analysis-and-its-efficacymechanism.asp\#.UbhBqdiDp30 [15.09.2012] 